Stepping Out of the Shadows: Supporting Actors' Strategies for Managing End-user Experiences in Service Ecosystems

Forthcoming in Journal of Business Research

May $4^{\text {th }}, 2020$

Vicky Story ${ }^{a *}$, Judy Zolkiewski a, Katrien Verleye ${ }^{b}$, Amin Nazifi ${ }^{d}$, Claire Hannibal e, Tony

Grimes $^{f}$, and Liliane Abboud ${ }^{b}$

a School of Business and Economics, Loughborough University, United Kingdom

${ }^{\mathrm{b}}$ Alliance Manchester Business School, The University of Manchester, United Kingdom

${ }^{c}$ Faculty of Economics and Business Administration, Ghent University, Belgium

d Strathclyde Business School, University of Strathclyde, United Kingdom

e Business School, Liverpool John Moores University, United Kingdom

${ }^{f}$ Sheffield Business School, Sheffield Hallam University, United Kingdom

* Corresponding author:

Prof. Dr. Vicky M. Story

Chair of Marketing

School of Business and Economics

Loughborough University

Loughborough, LE11 3 TU, UK

Phone: +44 1509228301

Email:v.m.story@lboro.ac.uk 


\title{
Stepping Out of the Shadows: Supporting Actors' Strategies for Managing End-user Experiences in Service Ecosystems
}

\begin{abstract}
In service ecosystems not all actors have direct relationships with end users, yet they are often critical for delivering better service experiences. Specific events (e.g. service failures) may require these supporting actors, who are often hidden during regular customer experience journeys, to become visible when deviations or disruptions occur. Deciding whether and when to come out of the shadows presents a complex managerial challenge for ecosystem actors providing supporting services, with important implications for end user's experiences. We examine strategies that service ecosystem actors can adopt for managing end-user experiences in complex ecosystems, and the implications for themselves and other ecosystem actors. Based upon two dimensions, visibility and synchronization, six experience management strategies are outlined and contrasted. Using case vignettes, we explore how and when such strategies might be adopted and potential impacts on service sellers and end-user experiences during regular and atypical service journeys, and present future research propositions.
\end{abstract}

Keywords: Customer experience management strategies, Supporting actors, Actor visibility, Ecosystem synchronization 


\section{Introduction}

Customer experience has been discussed extensively (Homburg et al., 2017; Kranzbühler et al., 2018), with Lemon and Verhoef (2016) highlighting the complexity and variety of the construct. Increasingly it is recognized that customer experience is not the sole remit of one firm but the responsibility of a complex ecosystem (Reimer \& Folkes, 2009). Ecosystems are "a relatively self-contained, self-adjusting system of mostly loosely coupled social and economic (resource integrating) actors connected by shared institutional logics and mutual value creation through service exchange" (Lusch \& Nambisan, 2015: 161) that can take many shapes and forms (Weill \& Woerner, 2017). These different shapes and forms influence ecosystem actor activities and end-user experiences.

Adopting a customer journey perspective recognizes customer experience as an iterative, dynamic process (Patrício, et al., 2018; Van Vaerenberg et al., 2019) that involves various interactions with other actors (Patrício et al., 2011). Although most touchpoints are controlled by the service seller, other supporting actors may be involved (Lemon and Verhoef, 2016). These actors often provide a key element of a service without being visible or directly connected to the end-user, for instance by providing the infrastructure (e.g., railway tracks or electricity distribution systems). Drawing on the theatre metaphor (Grove \& Fisk, 1983), these supporting actors would be 'backstage'. Nonetheless, some customers may occasionally encounter these hitherto hidden actors along their journey. For example, if a service failure occurs, these backstage actors may be required to directly interact with end users to provide service recovery activities. In doing so, these supporting actors could move 'front-stage', crossing the line of visibility. Conversely, backstage actors may choose to remain hidden, engaging in service recovery activities on behalf of the frontstage actor (i.e., service seller). Finally, it is possible that these actors might always be visible to end users. 
Backstage actors in the service ecosystem need to decide whether and when come out of the shadows or whether to remain hidden. These choices present challenges around managing touchpoints among ecosystem actors, in terms of both regular customer service experiences and dealing with atypical service journeys, i.e., deviations from or disruptions to the regular journey (Van Vaerenbergh et al, 2019). In an ecosystem context, customers' unfamiliarity with hidden supporting actors (who might only 'step out of the shadows' at certain times) may impact judgments of their experience with other ecosystem actors, particularly the service seller, who may stand to lose business (Van Vaerenbergh et al., 2014). Where end-user evaluations are important performance metrics within the service ecosystem, this could be extremely problematic. Typically, customer experience metrics reflect a culmination of customer experience episodes (Meyer \& Schwager, 2007). In situations where supporting actors only become visible for service failures, end users are likely to judge these experiences predominantly on the single episodic event, which, for service failure, is often a negative interaction. Conversely, customers who are cognizant of this actor's role, possibly because of previous positive interactions, may have a more balanced judgement of the service they provide (Gelbrich et al., 2016). As supporting actors in service ecosystems are often partly recompensed on customer satisfaction scores, these end-user assessments matter (Zolkiewski et al., 2017).

Clearly, supporting actors have a strategic dilemma with respect to the visibility of their activities during both regular and atypical service journeys. These journeys can also be influenced by the coordination efforts of ecosystem actors, whose integrated efforts combine to deliver services that customers value (Clarysse at al., 2014). However, ecosystem structures may vary for different service offerings and delivery modes (Bustinza et al., 2019), requiring varying degrees of actor synchronization (Jacobides et al., 2018). 
Little is known about the way in which supporting actors manage their visibility and synchronization with other actors or the implications of these decisions for other ecosystem actors. To address the paucity of research in this area, we explore the customer experience management strategies available to supporting actors in complex service ecosystems. Our contribution lies in the identification of two key dimensions (visibility and synchronization). Drawing from customer experience management theories, in combination with dramaturgy and the theatre metaphor, a typology of strategies is developed and illustrated with case vignettes (developed from secondary data) that exemplify how supporting actors manage their relationships with other ecosystem actors and end users, under regular and atypical (such as, service failure and recovery) service provision. A critical consideration of the benefits and challenges that these strategies pose for these and other ecosystem actors and end-user service experience judgements is offered. Finally, research propositions suggesting how and when supporting actors might benefit from adopting different experience management strategies are developed. In doing so, this work advances managerial practice and responds to calls to investigate customer experience management from an ecosystem perspective (De Keyser et al., 2015, Lemon \& Verhoef, 2016).

\section{Customer experience and its management in service ecosystems}

Customer experience researchers increasingly adopt a journey perspective, emphasizing interactions with a specific firm along multiple touchpoints (Lemon \& Verhoef, 2016; Voorhees et al., 2017). Here, touchpoints refer to physical, human, and digital points of contact with the service (De Keyser et al., 2015; Voorhees et al., 2017). Complementing this notion, ecosystem researchers argue that ecosystems of actors often bring complementary and coevolving capabilities to create value (Adner \& Kapoor, 2010; Aarikka- 
Stenroos \& Ritala, 2017; Moore, 1993). Business ecosystems are specifically defined as: 'the collaborative arrangements through which firms combine their individual offerings into a coherent, customer-facing solution' (Adner, 2006: 98), and configurational approaches vary depending on firms involved and services offered (Bustinza, et al., 2019).

Consequently, customer experiences reflect a holistic, multidimensional response to a complex set of interactions with a variety of ecosystem actors (Bitner et al., 2008; Tax et al., 2013). To understand these experiences, an in-depth understanding of the context in which experiences emerge, as well as the institutional arrangements pertaining to an ecosystem's norms and practices that shape experiences, is imperative (Verleye et al., 2017). However, there is a lack of understanding about how ecosystem actors coordinate and manage experiences.

Customer experiences stem from a complex set of interactions between ecosystem actors and the customer. These ecosystem actors may operate before and after the line of interaction (Bitner et al., 2008). Actors before the line of interaction (frontstage) directly interact with customers, whereas those after the line of interaction (backstage) interact indirectly. However, Bitner et al. (2008) also point out that actors are not necessarily visible to the customer and can operate in front or behind the line of visibility. Moreover, the line of visibility may differ between regular journeys and atypical journeys. The issue here is that actors can contribute to service delivery with or without the customer knowing. Indeed, many customers are unaware of the complex ecosystem of actors needed to deliver services. For example, they may not know that (in the UK) their energy supplier works with electricity generators and distributers to bring power to homes. Thus, customers might only become aware of hitherto invisible actors when those actors move frontstage to provide a specific service interaction (e.g. to fix a fault). 
Extant research suggests that actors in a service ecosystem might depend on one another in different ways (Bustinza et al., 2019), and that customer experience management in service ecosystems requires actors to engage in different types of relationships to address the complexities inherent in jointly delivering end-user services (Homburg et al., 2017). However, the amount of coordination or synchronization among different service ecosystem actors varies (van Riel et al., 2013). Compare a travel context, where supporting actors often play relatively independent complementary roles, with a healthcare context, where a highly synchronized set of actors work together to ensure a holistic patient experience. It is generally recognized that managing customer experience requires the design of touchpoints that are cohesive, consistent, and connected to one another in a multi-actor business ecosystem, and that this should ensure better customer and firm-related outcomes (e.g. Homburg et al., 2017). However, the appropriate level of ecosystem actor synchronization in regular versus atypical journeys is not yet known.

\section{Metaphors, Dramaturgy and Marketing Theory Development}

A metaphorical and dramaturgical approach is proposed to help explain how visibility and synchronization decisions guide supporting actors' customer experience management strategies. Metaphors allow the transfer of meaning, ideas and information already known about one domain (the source domain) to the explored domain (the target domain) (Van den Bulte, 1994). In doing so, they facilitate the reassement of existing principles and the development of new insights (Cornelissen, 2003). Tsoukas (1991) argues that a metaphor is 'operationalized' by exploring the analogies (the 'are like' aspects) inherent in the metaphor domains. They are widely used in service research (Bitner, 1992; Akaka et al., 2013). Linked to the use of metaphors, and as a metaphor in and of itself, 
dramaturgy provides the means to gain insight into front and backstage performances, and their implications for different actors. Frontstage is where the performance happens for the audience while backstage is beyond what the audience sees (Goffman, 1959). Depending on the performance envisioned by the director, some actors (e.g. the technical crew) might remain completely invisible to the audience (backstage or behind curtains), may be partially visible (e.g. unobtrusively dressed in black during set changes), or sometimes completely visible (e.g. becoming part of the performance to affect set changes). Thus, frontstage and backstage are nuanced concepts.

Most performances involve a team of actors who cooperate to create the desired reality (Goffman, 1959). Good performances are often thought to require a common bond between actors, which enables individual actor performances to become a coherent, authentic performance experience for an audience (van Riel et al., 2013). To achieve firm level synchronization, organizations are known to design, script, stage and perform their service activities to make experiences memorable (Holt \& Thompson, 2004). However, operating in an ecosystem with visible and less visible actors is complex, and service experiences are often more difficult to script, stage and perform. Hence, actor choices about the extent of synchronization have important implications for the experience. Understanding decisions about visibility and synchronization will provide important knowledge about how these strategic decisions impact themselves, other ecosystem actors, and customer experience.

\section{Proposed framework - Supporting Actors' Customer Experience Management Strategies}


Drawing on customer experience literature and the dramaturgical perspective, we propose that supporting actors' customer experience management strategies vary along two dimensions: visibility and synchronization (see Figure 1).

Insert figure 1 here

\subsection{Dimension 1 - Visibility of Supporting Actors}

A key strategic decision for supporting actors regarding their service activities is deciding how visible they are to end users. However, the line of visibility is not always completely clear-cut; actors can be invisible, partial visible or fully visible to end-users. Thus, visibility of supporting actors is situated on a continuum from 'low' to 'high' and relates to: the extent to which end users are able to recognize the presence and role of supporting actors during experience journeys.

Supporting actors in a service ecosystem make strategic decisions about whether to remain hidden behind frontstage actors, either permanently (staying behind the line of visibility) or until an atypical journey occurs (e.g. during a service failure), where they might then become visible. Alternatively, rather than stepping out of the shadows only when required, they may decide that the benefits of proactively highlighting their role (always frontstage), in terms of customer relationship building efforts, outweigh the costs and risks of being visible (Zomerdijk \& De Vries, 2007). A key factor in the decision may be how frequently a supporting actor is required to directly interact with end users, because the first time an actor 'steps out of the shadows' will need to be managed differently than subsequent interactions, where knowledge of this actor has already been built. There is inherent difficulty in delivering low visibility strategies where there is a requirement to 'step 
out of the shadows' to deliver key service interactions when customer experience journeys are disrupted. These visibility choices also have implications for other ecosystem actors.

\subsection{Dimension 2 - Supporting Actor's Synchronization with Service Sellers}

The synchronization dimension is driven by the need for actors to deliver a coherent end-user experience (Jacobides et al., 2018). Synchronization focuses on the temporal relationship of activities (Perks, 2005) and reflects the amount of active coordination between actors across multiple service interfaces (Patrício et al, 2011). As with visibility, supporting actor synchronization can range from low to high, and is defined as: the temporal coordination needed between supporting actors and service sellers with regard to the activities involved in delivering a seamless customer experience journey. High synchronization equates to close coordination amongst actors; it highlights shared norms and goal alignment (Akaka et al., 2013), team-working (Håkansson et al., 2009); and knowledge sharing (Möller, \& Halinen, 2017). However, synchronization may not always be necessary or preferred. It is well known that organizations adopt different cooperative approaches, from arm's-length to more collaborative arrangements (e.g. Dyer and Singh, 1998), with each conferring different benefits and drawbacks (Jacobides et al., 2018). Highly synchronized activities can allow all actors to perform better with regard to customer service provision; equally, it can make it difficult to clarify the scope and contribution of individual actors (Fjeldstad et al., 2012). Low synchronization equates to supporting actors taking a more independent approach to the delivery of their service activities. Actors may choose a low synchronization strategy because they are better able to manage their part by remaining independent, or potentially, other actors may not agree to collaborate, forcing actors to operate independently. Equally, supporting actors adopting a high synchronization approach may have to align themselves with the direction set by one or more central actors 
(Clarysse et al., 2014). As with visibility, synchronization strategies might operate effectively for regular but not for atypical journeys.

\section{Experience Management Strategies}

We describe six experience management strategies that result from adopting different positions along the visibility and synchronization dimensions (see Figure 1). We illustrate the potential benefits and challenges that might arise for supporting actors, service sellers and end-users through exemplar vignettes from the energy, air and rail travel sectors ${ }^{1}$. All involve front and backstage service providers, facilitating exploration of lines of visibility. They include regular and atypical service experience interactions that illustrate the benefits and drawbacks of different scenarios. Furthermore, different actors within similar contexts adopt different approaches, i.e. we see variability across dimensions. Finally, their regulatory and institutional environments make their contexts comparable. For example, air travel comprises a variety of elements; the core service, which is transportation from point A to point B (including check-in, baggage handling, security, boarding); and non-core services (such as in-flight meals and airport lounges). Some services are offered by visible actors, but many are provided by less visible supporting actors, and some actors adopt a high level of synchronization, and others are less synchronized.

\subsection{Low Visibility - Low Synchronization Strategy}

\footnotetext{
${ }^{1}$ The sources used to develop the case vignettes are provided as a supplementary file.
} 
In this strategy, the service seller's role is foregrounded during regular journeys and

supporting actors operate as independent, invisible, service providers. In atypical journeys,

supporting actors have a choice of remaining hidden behind the service seller or becoming

fleetingly visible to end users. Following such incidents, supporting actors usually return

backstage. In terms of synchronization, these supporting actors adopt a relatively

independent approach to the ecosystem.

\section{UK Power Networks Vignette}

UK Power Networks is an electricity distribution network operator (DNO) in the East and South East of England. Whilst they are responsible for providing power, there is no requirement for direct end-user contact, as metering, billing and informational needs are served by an electricity 'supplier' (e.g. EON, Npower). Suppliers sell electricity; DNOs manage and maintain electricity cables. The scope and contribution of each actor is distinct but not visible to end users. The ecosystem is heavily regulated by the Electricity regulator, Ofgem.

End users are usually unaware of UK Power Networks' role in the ecosystem. Contact is rare and sporadic, e.g., when a change of power supply or overhead power line maintenance is required, or for restoration of a power failure (which occurs on average every 9 years). In these instances, despite the DNO being responsible for installing/repositioning electricity meters, end users are required to communicate with their electricity supplier; they only engage with the DNO at installation. However, when a fault occurs, DNOs engage directly with end users; electricity suppliers are not involved. The DNO is, therefore, relatively invisible for 'routine' atypical interactions (e.g. maintenance), but visible during critical atypical incidents (power failure). Furthermore, UK Power Networks do not work with service sellers or other ecosystem actors to actively synchronize their interactions. This arm's-length approach is evidenced in the way energy suppliers seek to pre-emptively deflect customer enquiries about power cuts to DNOs (by promoting a national telephone helpline that automatically connects end-users to their regional DNO). Equally, no connections to partners are made on UK Power Network's homepage; the focus is solely on them being ready to respond to power cuts.

However, a strategy of remaining invisible whilst providing an effective service creates risks. These are usually apparent on the rare occasions when the service fails (i.e. a power outage) and the DNO is the primary point of contact for end users, but has no prior relationship to draw on. End users' unawareness of the company's role in continuous power provision may just assume that their role is simply 'power restoration'. The difficulty in diagnosing the root cause of a power outage, means that UK Power Networks uses average resolution times to provide an initial estimate. This estimate is often inaccurate (because some factors cannot be predicted in advance, e.g. a car parked over the manhole cover to which access is required). If UK Power Networks do not restore power by the estimated fix time, end users perceive a service failure. It is at this point that most complaints occur. Examining feedback on the Trustpilot review site shows that restoring power in adversity draws highly positive reviews, with comments focused on working in difficult conditions, going the extra mile, appreciating 
being kept updated. Also, terms like efficient, professional and friendly crop up regularly. However, negative feedback highlights a lack of reliable estimates about power restoration, conflicting messages being received, and repeated 'fail' incidents.

Here, the regular journey is managed by the front-stage actor. UK Power Networks' role in continuously providing power goes unnoticed. Thus, UK Power Networks do not get credit for all the time the service is provided fault free. This strategy appears advantageous to service sellers, who essentially take credit for supplying power. It also appears advantageous to UK Power Networks, in the sense that it does not need to invest resources in being visible and managing ongoing relationships with end-users. During minor atypical journeys (e.g. installations/maintenance), end-user interactions with UK Power Networks are minimal, coordinated by the frontstage actor and kept to only that which is necessary to complete the task. However, low visibility may matter when there is no power. In this context, end users want someone to contact who will fix the problem. Due to the low visibility of UK Power Networks, major 'service failures' (power cuts), are often initially presumed to be the fault of an otherwise dependable, electricity supplier. If UK Power Networks remained invisible, end users would only have the visible actor to focus on. However, the provision of the emergency telephone number means that UK Power Networks must take responsibility at this point and cannot remain invisible. Based on the wealth of available online information, and the proactive approach to customer complaint messages registered (e.g. on Trustpilot), UK Power Networks clearly take the need for visibility seriously at this point.

From a service recovery perspective, the fact that these actors are usually invisible to end users may be of no consequence, because their ability to 'save the day' (restore power) can outweigh all else. However, sometimes efforts might be hampered by other actors and external influences (e.g. storms and floods), leading to customer dissatisfaction. Here, a low 
visibility/low synchronization strategy may prove problematic for supporting actors. For UK

Power Networks, becoming visible during atypical interactions means that end users will be able to attribute at least some service failure blame to them; a company with which they have little or no prior experience or knowledge of with respect to their trustworthiness or credibility. If end users have come across them before, they either have a positive experience to draw from or a negative one, e.g., previously failing to restore the power in a timely manner. The more frequent and more critical outages are the more likely negative judgements will develop (Keiningham et al., 2014). However, because customers like to apportion blame (Van Vaerenbergh et al., 2014), it is possible that they may also perceive a failure on the part of the service seller. The fact that all parties are scrutinized by the regulatory body, and performance metrics are monitored, should drive efforts towards positive end-user outcomes, but low synchronization can hamper this.

\subsection{Low Visibility - Moderate Synchronization Strategy}

In this strategy supporting actors have some ties with other service ecosystem actors but choose to be backstage with regard to their visibility, unless (or until) events require them to emerge from the shadows.

\section{Skeyes Vignette}

Skeyes is a Belgian public company. They ensure the safety and efficiency of air traffic in Belgium 24/7 and are responsible for air traffic control infrastructure. For many years, they have delivered their service activity as an invisible third party, leaving airports and airlines to interact with end users. In terms of synchronization, Skeyes has no direct touchpoints with end users during the customer journey but does have direct touchpoints with airlines and airports, which, if not operational, negatively affect customer experience. Synchronization is moderate; they do not collaborate extensively with other actors to coordinate user experience. For example, while they must exchange information with partners on flight takeoff slots, they make decisions about air traffic control based solely on safety. Skeyes do not engage in additional brand awareness/relationship management efforts and service sellers receive credit for on time flights. However, in EU countries there is complex legislation about who compensates end users in atypical situations. If it can be attributed to a problem under 
the control of the airline, such as aircraft faults, the airline is responsible. However, under 'exceptional circumstances', such as weather conditions or strikes, the airline is not responsible, but still typically has to deal with customer complaints.

In both regular and atypical journeys, Skeyes remains invisible. However, the complexity of supporting actors becoming visible is exemplified by the following incident. As the workload for Skeyes air traffic controllers increased, they argued that this was having negative implications for the safety of air traffic, because staff were exhausted. In 2018, the air traffic controllers decided to take strike action, resulting in air traffic interruptions in many Belgian Airports. Some 188,500 passengers at Brussels airports saw flights delayed or cancelled. Through this strike action Skeyes became more visible to end users, with air traffic controllers stepping out from behind the line of visibility to make their voices heard. Communications, press releases, and even placards all foregrounded the Skeyes name. This action caused major problems for other ecosystem actors, in the form of serious economic loss and reputational damage and significantly impacted user experiences.

Extrapolating from the Skeyes case, under regular operating conditions, firms may well be able to work with other ecosystem actors in a moderately synchronized way that allows them to focus on their individual goals, but also remain invisible. Operating backstage in this way may be advantageous, but for their partners, particularly those that are the more visible face of the ecosystem, they can be difficult actors to work with. For example, when flights are delayed, it is the visible actors that bear the brunt of negative feedback, and, in the EU, may also be responsible for providing compensation. In terms of the strike, several other ecosystem actors were confronted with significant economic losses and reputational damage. Invisible actors, however, may also suffer from becoming visible. In this case, Skeyes did not want to step out of the shadows but was forced to by the actions of its employees. The increased visibility around safety issues created traction for the employees' cause, but also led to reputational damage for Skeyes. Skeyes are now visible, but their reputation is not one they would want and could potentially jeopardize their image as a reliable third-party provider. In this instance, service sellers might conceivably see merit in being only moderately synchronized with these actors; so that they can distance themselves, if necessary. 


\subsection{Low Visibility - High Synchronization Strategy}

Actors adopting a low visibility, high synchronization strategy choose a backstage, low visibility position, but work closely with the frontstage service seller to provide a more synchronized approach.

\section{Menzies Vignette}

Menzies Aviation provide essential airport support services, including baggage handling service (BHS), cargo and aircraft refueling in over 200 airports worldwide. Airline customers (end users) expect their bags to arrive safely at their destination in a timely manner. Provided correctly, this service does not lead to a positive evaluation. Indeed, airline passengers often have no idea what happens to their bag between checking it on departure and collecting it at their destination. Therefore, baggage handling actors, whilst an integral part of the service, are often not visible to end users. However, in terms of synchronization, Menzies work closely with airlines. The bags are tagged either by the airline crew or an automated system, but are checked, loaded and unloaded by Menzies. They work closely with airport operators to access key baggage handling areas and obtain all the information necessary to ensure baggage gets to the right aircraft. This level of coordination is required to meet safety standards (e.g. distancing baggage staff from the plane while refueling is taking place). The overall service is highly synchronized; all actors need to share bag bar codes and, given the inherent risks involved in key operations (e.g. refueling), collaborative approaches are essential. Indeed, it is common for shared training to build shared understanding and safety protocols.

To avoid baggage delivery problems, Menzies rely on auditing activities, such as counting bags or checking total flight bag weights, as well as occasional hidden camera checks to monitor process/theft activity. However, baggage delivery problems do occur. Atypical incidents include bags that take longer to arrive at baggage carousels, bags that miss connecting flights, and damaged or lost bags. Most delays cause minor inconvenience to passengers, but, in some instances, bags go missing for longer or are mishandled during transportation, causing damage. These are more major issues and can often be linked to employees not handling the bags well. Baggage staff are often poorly paid, and the job can see high staff turnover rates. When issues arise, it can lead to negative customer reactions. In order to mitigate these, Menzies has a system where customers can check their lost/delayed bag status using an online tracking system and they also deal with damaged bag claims. At this point, end users interact directly with Menzies, who become visible to fix service failures.

In this scenario, Menzies coordinates their efforts with the service seller and shows some evidence of focusing on supporting these actors to achieve their objectives. This is evidenced through all the checking procedures they have put in place to work with airlines to get bags to their destination. During a regular journey, if bags arrive, on time and 
undamaged, there is no need for Menzies to be visible. The benefit to end users is that there is less confusion. However, service failure episodes are different. If backstage actors remain hidden, leaving frontstage service sellers to deal with complaints, there is less incentive for hidden actors to fix issues promptly. As outlined in the UK Power Networks vignette above (above), the risk for service sellers operating with a hidden provider can be high, as they shoulder the blame and negative feedback (for example, Munich airport operates a system of airlines being the contact for baggage claims, with the baggage handling actor AeroGround Flughafen Munchen $\mathrm{GmbH}$ - remaining hidden). Thus, even though airlines do not handle bags themselves, customers do not hesitate to blame them for baggage failures (Coffey, 2019). Given that airlines are under scrutiny for a wide range of issues, such as flight overbooking (Tiernan et al., 2008), they can be reluctant to accept blame for other actor's failures, and can be quick to divert blame to supporting actors. For example, EasyJet warned passengers that they needed to arrive at Manchester airport at least three hours early due to Menzies baggage handling issues (Abbit, 2019). Finally, in some cases, the support actor can lose the contract. DHL now manage EasyJet's ground handling operations at Manchester, taking over in February 2019 (Burns, 2018). Ultimately, it is in the best interest of both parties (i.e. airline and baggage handling company) to work in a highly synchronized manner to offer a seamless service. When actors adopt a high synchronization strategy, it is more likely that a hidden actor will behave cooperatively. By selecting backstage actors who adopt a synchronized strategy, a service seller may well be looking to mitigate risks. What is interesting here is that Menzies take responsibility for service failures, and have created systems to help communicate with customers during these incidents. Although Menzies does step out of the shadows for baggage handling errors (shifting the focus of end users' negative emotions from airlines), they do not seem to focus efforts on reducing these 
failures. Baggage handling services are often managed by third parties to reduce operational cost. Thus, while there is evidence of synchronization, Menzies overriding driver is likely to be cost, which may not be consistent with desired behaviors from a service seller perspective. Ecosystem actors might, therefore, need to decide whether to keep backstage actors at arm's-length, and have more explicit contractual terms and performance metrics, or work with them more closely to realize synchronization benefits.

\subsection{High Visibility - Low Synchronization Strategy}

Firms adopting this strategy take a largely visible position and operate relatively independently. The company foregrounds the fact that its primary role is to reliably provide a supporting service, but without necessarily synchronizing with other actors.

\section{Northern Powergrid Vignette}

Northern Powergrid is a DNO that covers the North East of England. Synchronization is low, with limited coordination with respect to customer experience and few interactions with end users on a day-to-day basis (as with UK Power Networks). However, Northern Powergrid assume a visible role in the service ecosystem by proactively engaging in regular marketing communications and advertising campaigns. For example, they have active Twitter and YouTube accounts promoting their achievements in consistently and reliably providing electricity. Promoting a customer-centric ethos, a Customer Engagement Group is used to challenge and shape their future plans to meet customers' needs. They also publicize their involvement in gamification efforts designed to engage and empower end-users to cut their electricity consumption and costs. Their homepage covers information about all their services, from power cuts and getting connected, through to other services (e.g. priority service register, service alteration, and temporary protection from overhead lines). Thus, they not only promote the fixing aspect of their role, but also the ongoing role of keeping the power on and other key services.

Whilst such visibility does not come without risk (e.g. end users more clearly attribute blame for power outages to Northern Powergrid), it also potentially confers benefits. For example, they can receive credit for the continuous, unbroken provision of power. Additionally, their efforts to inform end users about factors that are beyond their control (e.g. storms and floods) helps to mitigate against negative responses from end users.

The question here is: do firms have more credibility with customers if they highlight their on-going role in the customer's value creation process and that, if something goes 
wrong, they will strive to put it right? In doing so, Northern Powergrid aims to get more credit for what the company does right, day-in and day-out (i.e. effectively and efficiently keeping the power on) rather than just for how it resolves occasional failures. However, exploring differences between this strategy and that of UK Power Network; UK Power Network currently has a higher customer satisfaction score $(8.74 / 10)$ than Northern PowerGrid (8.64/10), but a lower stakeholder engagement score (7.25 as opposed to 7.5/10) (Ofgem, 2019). Thus, one might conclude that visibility does not positively influence customer satisfaction. Potentially, the low synchronization approach produces less coherent experiences, which mitigate any visibility gains. However, robust empirical research of this question is needed before such conclusions can be drawn.

\subsection{High visibility - Moderate Synchronization Strategy}

This strategy has visible supporting actors, operating frontstage alongside service sellers, clearly positioning their role in supporting regular journeys and working reasonably closely with other ecosystem actors.

\section{Fraport Group Vignette}

Fraport Group is one of the world's largest air services providers, operating 30 airports worldwide on four continents. In 2018, they welcomed nearly 70 million passengers at Frankfurt Airport and handled around 2 million metric tons of cargo. In addition to working with airlines and other ground handling actors, they also work with retailers to create the airport experience; seen as fundamental for the future economic viability of airport operators. Frankfurt Airport is an important air transportation hub and serves as the main European Star Alliance global network hub. This position and these connections provide significant benefits for Fraport Group regarding performance outcomes.

Fraport has a well-recognized brand that is visible both around the buildings and in terms of staff clothing. Committed to offering customers better and more tailored services, they regularly undertake market research to understand what end users (travelers) want, and then assemble a mix of retailers and to ensure both end-user satisfaction and performance outcomes for retail service providers. They trade on being a recognizable brand, for which visibility is essential. 
In terms of synchronization, they adopt a position of 'efficient cooperation'. Their focus on support services and the airport environment is consistent with the Group's commitment to ensure all passengers have a good trip. Fraport is a dominant player, articulating clear plans for their own growth and profitability and expecting partners to work within these plans. Fraport compels business partners and suppliers to comply with its Supplier Code of Conduct. Any partners violating this code can have their business relationship terminated or contractual penalties imposed. They have clear oversight of customer experience across the service ecosystem, but do not exhibit close synchronization with other actors. They also cooperate closely with regional stakeholders to minimize the negative effects of their airport operations.

This approach appears to make Fraport a highly desirable partner for airline companies, with the company signing new contracts and showing record passenger growth figures in 2018 and 2019 (despite a difficult climate). However, service failure issues do arise. Airlines had to cancel flights in May 2018 due to an IT system failure at Frankfurt airport. Only 70 of 1,560 planned flights were cancelled, but 23 were Lufthansa flights, Frankfurt's main airline. A baggage distribution system incident in September 2019 (linked to a Fraport system failure) caused 30,000 bags to be left in Frankfurt. This again disproportionally inconvenienced Lufthansa, who had to pay out passenger compensation, before claiming this back from Fraport.

Fraport provide the place in which a key part of a customer's flight experience occurs. The airport experience is a core part of a flight and Fraport essentially manage the servicescape for several key interactions, e.g. check-in desks, security, boarding gates. They then add value to the experience through the assortment of retail facilities end users can experience. Fraport's visibility appears to help them grow their business. Their brand reputation has enabled significant business growth, based on a reputation for aviation expertise. The vignette evidences the Fraport Group taking a proactive approach to contracting, pushing partners to sign up to their Supplier Code of Conduct. This approach potentially mitigates friction that could occur in a less synchronized ecosystem by making clear what Fraport expects from its supporting actors, especially given that fracture lines can be based on different interpretation of goals or what the right problem solution is. Other actors are willing to sign up to the code to work with Fraport because of their high visibility delivers a strong reputation and global reach. However, the two examples in the vignette show that Fraport's support service failures occasionally cause service sellers problems from 
the resulting atypical experience journeys. Interestingly, there are clear lines of

responsibility for different aspects of the service, and assurances about service failures by

different actors. For example, even though the airlines pay out compensation, they can

claim this back from Fraport, if they are at fault.

\subsection{High Visibility - High Synchronization Strategy}

In some ecosystems it may be possible to create a highly synergistic approach; where

support actors are visible and where actors' goals and actions align to create coordinated

end-user experience journeys.

\section{Network Rail Vignette}

In the UK, rail transport is a complex, highly synchronized service ecosystem with many visible actors. The actors include: 31 regionally based Train Operating Companies [TOCs]; Network Rail [NR]; the Office of Rail and Road [ORR], part of the UK Government; the Rail Delivery Group [RDG]; and independent ticket sellers.

Whilst TOCs own rolling stock (engines and carriages) and run passenger services, NR own and manage infrastructure (e.g. rail track, bridges, signal and level crossings), rail timetabling and 20 of the largest stations in England, Scotland and Wales. The TOCs and NR work closely on timetabling, the re-routing of services during planned infrastructure maintenance, and service failure and recovery activities. End users mainly interact with TOCs, but rail tickets can also be purchased via websites/apps, and at rail stations. The third-party ticket sales websites/apps (e.g. Trainline) sell tickets on behalf of the TOCs but are not involved in any other activities (e.g. service recovery).

NR has adopted a highly visible strategy, with strong branding on their vehicles and employee clothing, and active social media accounts. They see their role as providing the best possible service to everyone who relies on the railway. This highlights that their direct customers (e.g. the TOCs) and end users are their target audience. However, despite this focus, they can be less visible to end users on a day to day basis, but then attract high-profile press exposure at times of service failure (e.g. when track issues disrupt travel or timetables are changed). End users often become more aware of NR during these situations, and so the perception of NR may be less positive than that of the TOCs, because their prior visibility makes it clear that they are responsible for these issues. Evidence shows an element of ecosystem actors 'passing the buck' when failures occur, with station announcements varying in content regarding why a train is delayed.

All ecosystem actors are members of the RDG, a body that represents the UK rail industry and provides a forum for leading and coordinating improvement initiatives. The RDG is responsible for working with members to coordinate the national rail timetable and appears key to the high synchronization strategy. 
The ORR, an independent regulator, is responsible for setting rail transportation service strategy and overseeing its implementation, including setting and reporting on reliability and punctuality performance targets, and health and safety compliance. This regulation creates institutional pressures for all parties to maintain quality standards. For example, NR was previously asked to submit a report to ORR relating to deficiencies in performance planning and service recovery procedures, due to their industry performance figures. This report outlined plans for improving collaboration with ecosystem actors to support performance improvements, and for investing in more sophisticated technology to help them monitor performance better and restore services quicker when failures occur.

This strategy initially appears to be a scenario that produces win-win outcomes from high synchronization of activities and the fact that all parties are visible and, thus, accountable for their actions. However, it requires a desire on behalf of key actors to provide resources to support the creation of these close ties and to work together in a highly synchronized way. Industry regulation promotes high synchronization, but, where there are numerous direct providers, all operating in a competitive marketplace, there might be limited desire by supporting actors to invest in the necessary activities to achieve this in practice. Indeed, it may be impossible for Network Rail to have close relationships with multiple competing actors in the network or ecosystem (Håkansson et al., 2009). Furthermore, for atypical journeys, outcomes are not always satisfactory for either TOCs or end users (for example, being stuck behind the 'slow train', after your 'express train' was delayed). Thus, synchronization being high, this may not be sufficient to deliver good customer experiences.

\section{Discussion and Research Propositions}

The framework (Figure 1) proposes that supporting actors face key strategic decisions with regard to determining the optimum degree of visibility to end users and the appropriate level of synchronization with service sellers. The vignettes, which illustrate these strategic decisions, facilitate comparison of the potential benefits and limitations of 
various approaches. Central to these decisions is the issue of regular versus atypical service provision. What emerges is a sense that supporting actors are faced with dilemmas about how best to manage customer experience over time. These are now captured in a series of propositions.

\section{Propositions related to Visibility}

Firstly, the vignettes suggest that for regular journeys, low visibility offers cost benefits to supporting actors by making investments in brand communication redundant. By contrast, supporting actors that adopt a high visibility strategy for regular journeys must continuously invest in communication to highlight the integral nature of their involvement in the experience. This is important if they are to receive credit for what they do and to develop a 'reservoir of goodwill' (Jones, Jones \& Little, 2000).

For regular journeys, comparing Network Rail and Northern Powergrid against UK Power Network, Skeyes and Menzies suggests that low visibility confers more benefits than high visibility. It also appears to confer greater benefits on service sellers and is less confusing for end users. In comparison, high visibility does not appear to bring direct financial benefits for Network Rail or Northern Powergrid, but does appear to increase the extent to which they receive credit for regular service delivery (which is shared with, rather than ceded to, service sellers). However, this reputational benefit does not appear to impact customer satisfaction metrics. One reason for this might be that the sharing of credit for service provision is offset by the impact of an increase in customer's information processing (with regard to who does what). Thus, supporting actors adopting a low visibility strategy will benefit from reduced costs in relation to branding and marketing communication, 
sellers benefit from receiving credit for activities that they are not responsible for and end users benefit from not having to make sense of a complex ecosystem. Thus, we propose:

\section{P1: For regular journeys, low visibility of the supporting actor should benefit both the} supporting actor and the service seller to a greater extent than high visibility and does not significantly affect user experiences.

An important implication of our framework is to show how customers may perceive the same actions in different ways, depending on the supporting actor's prior visibility. Our conceptualization highlights the need to understand whether end users perceive themselves to be on a service journey (involving consistently visible supporting actors) or a service recovery journey (involving previously invisible actors that step out of the shadows). For example, Northern Powergrid visibly promote their role as 'providing power', thus, it is reasonable to assume that a power outage will be viewed as a 'service failure' by end users and efforts to restore power will be seen as 'service recovery'. However, where a previously 'invisible' power distribution company (e.g. UK Power Networks) only chooses to emerge from the shadows when a power outage occurs, this act becomes the service provision (i.e. 'power restoration'), so a service failure will only be perceived if they do not restore power in a timely manner.

The benefit for supporting actors of emerging from backstage earlier in the performance (a high visibility strategy) is that it builds their reputation prior to service failure. This should foster understanding, tolerance and positive dispositions toward the actor during service failures and result in more balanced service experience perceptions (i.e. the perception of reliable service provision). Therefore, for supporting actors, the benefits of adopting a high visibility approach may be felt during atypical, rather than regular journeys. This choice also impacts service sellers and end users. For example, for Northern 
Powergrid and Fraport, prior knowledge of these companies, means that end users know who to contact in the event of service failure. This reduces confusion at a stressful time and, due to previous interactions, reassures end users that the problem will be resolved. End users can also apportion blame to the right actors, which benefits service sellers. For example, when end users understand Network Rail's role, they are less likely to blame TOCs for failures that are out of their control. Furthermore, customers are more likely to forgive organizations for service failures when they have a good existing relationship (DeWitt \& Brady, 2003).

In contrast, a supporting actor's low visibility strategy means they have no prior credibility with end-users. Instead, they may be considered specialist service recovery actors. When failure occurs, service sellers may, thus, take a reputational hit. For example, UK Power Networks get no credit during regular journeys, due to their low visibility; all the credit goes to the service seller. However, when power fails, the fact that end users think that the service seller also supplies power can mean they are blamed. The emergency telephone phone number helps to mitigate this service seller disadvantage, by pointing end users to the supporting actors. For UK Power Network, this number means that they then become visible. For Northern Powergrid, presumably, this 'pointing' is not required because end users already know them. Thus, we propose that:

P2: For atypical experience journeys, high supporting actor visibility should enhance enduser experience perceptions with regard to service recovery, and reduce negative reputational consequences of failure for both supporting actors and service sellers to a greater extent than low visibility. 
Decisions as to the level of desired visibility amongst supporting actors may be complicated by other factors, such as the likelihood of deviations, difficulties of predicting recovery, and the nature of the service experience.

When service disruption is infrequent, low visibility might be a better choice, because investment in visibility might outweigh the reputational benefits gained. Furthermore, these actors can benefit from stepping out of the shadows to 'save the day'. For example, customer feedback about UK Power Networks suggests that end users appreciate that they are working in difficult conditions to get their power back on. Potentially, this and the relative infrequency of power outages is why, compared to UK Power Networks, Northern Powergrid fails to benefit from their high visibility strategy. Presenting its service as 'the continuous provision of power' means that it is only perceived to have failed occasionally (approximately once every 9 years). However, Burgoon, (1993) suggests that conformity of most behaviors to people's expectations will go unnoticed. Thus, if failures are infrequent then, potentially, the benefits accrued from delivering continuous power are overlooked. In these circumstances, maybe there is a trade-off between the cost benefits and the reputational risks attached to the likelihood of failure that points to the benefits of a low visibility strategy outweighing a high visibility strategy for both regular and atypical journeys. This is illustrated by the dilemma faced by Skeyes, who were forced out of the shadows by the strike action, and then needed to either slip back into the shadows or spend considerable resources rectifying the reputational damage, which might then be undermined by further service disruptions.

In exploring the implications of service recovery activities under different strategies, we recognize that failing to deliver a service as promised can cause negative customer perceptions. For visible supporting actors, the perceived failure to continuously provide a 
given service may be compounded by a second perceived failure. This can lead to perceptions of a 'double deviation', which can have major negative consequences in relation to customer satisfaction (Joireman et al., 2013), particularly for frequent failures (Van Vaerenbergh et al., 2014). Thus, when service recovery is difficult to predict, being visible might be a bad idea. For Northern Powergrid, while failure remains a very infrequent occurrence, the initial failure (to provide power) may well be compounded by a second failure (to restore power when promised), leading to additional negative perceptions amongst end users.

With respect to visibility, the benefits of 'continuously' providing a service for discrete, episodic services may be different than for ongoing services; the type of service journey can influence how customers react (Swanson \& Kelley, 2001). Whilst prior research has considered various aspects of service failure and recovery, it has tended to focus on discrete failures (Van Vaerenbergh et al., 2019), rather than related failures involving various ecosystem actors. This warrants further exploration.

\section{Propositions related to Supporting Actor's Synchronization with Service Sellers}

The vignettes suggest that synchronization decisions are linked to the supporting actor's role. For regular journeys, synchronization costs and benefits appear linked to the type of support service provided. In the case of Menzies, baggage handling activities are contingent upon, and coordinated with, other aspects of the experience. Thus, for the enduser experience to be seamless, synchronization is required. This is also true for Fraport, who need to coordinate many interdependent activities on behalf of the service sellers (airlines), and for Skeyes, who need to work with the airport and airlines to ensure that flights take off as scheduled. Network Rail must also coordinate with the other actors to 
ensure a seamless customer journey. In contrast, end users of UK Power Networks and Northern Powergrid are not likely to encounter service experience issues despite low synchronization, because the main activity (providing power) is managed independently. Thus, we propose:

P3a: Where there is clear delineation between roles, low synchronization is as effective as moderate and high synchronization with regard to end-user experience perceptions; but, where there are blurred boundaries between roles, moderate and high synchronization approaches perform better than low synchronization.

In terms of supporting actor and service seller outcomes, when the supporting actor activities are discrete, the costs for supporting actors and service sellers of synchronizing their operations appear to outweigh the benefits. However, the benefits outweigh the costs for all actors when user experience activities are intertwined (i.e., where systems and processes support useful collaboration). For example, UK Power Networks and Northern Powergrid benefit from a low synchronization approach because they can undertake their activity independently. Service sellers also benefit from their performance, without investing in coordination efforts. Greater synchronization between these actors would not affect the end-user experience for regular journeys, but would increase costs.

The vignettes illustrating moderate synchronization show more supporting actor benefits. Skeyes have some coordination with other actors but tend to be relatively independent in their decision-making. While they have good information flows between actors, they do not work closely with airlines; they dictate decisions based on safety and efficiency requirements. Thus, there is some investment, but it is neither extensive nor focused on close cooperative interactions. Fraport also coordinate with ecosystem actors to ensure everything happens as it should, but this coordination has an element of control 
rather than interdependence. This approach is likely to be less costly than high

synchronization, while offering enough coordination to confer benefits on both the supporting actor and service seller during regular journeys.

High synchronization potentially increases costs for all actors in terms of investing in coordination efforts. However, these shared synchronization efforts are also likely to lead to efficiency and effectiveness gains, when activities are interrelated. For example, the shared training between Menzies and their service sellers helps both parties to offer a better experience and deliver the service more effectively. Network Rail also appear to benefit from their synchronization efforts, as do TOCs. Thus, we propose:

P3b: Where there is clear delineation between roles, low synchronization confers greater benefits to supporting actors and service sellers than moderate and high synchronization; where there are blurred boundaries between roles, moderate and high synchronization confer greater benefits to supporting actors and service sellers than low synchronization.

The benefits of full synchronization might, however, be most evident during journey deviations. In such circumstances, actors that have low synchronization must unilaterally coordinate end-user interactions. This is likely to require investment in communications, scheduling systems and training for service recovery staff. As seen in UK Power Networks customer reviews, end users clearly dislike unreliable estimates and conflicting messages, but like professional, friendly staff that go 'the extra mile'. Low synchronization allows service sellers to distance themselves from failures.

Moderate synchronization appears to offer a compromise between coordination and control for supporting actors. It also has strengths and weaknesses for service sellers, but delivers poorer end-user experiences. For example, Skeyes has control of flight decisions, so synchronization is more informational (e.g. changes to flight times); this can be extremely 
frustrating for end users and while airlines have no ability to influence decisions, they bear the brunt of complaints. Thus, both service sellers and end-user experiences are negatively affected. Menzies vary their synchronization approach for atypical journeys, moving to a low synchronization approach at failure and taking responsibility for fixing failures. It seems, therefore, that while high synchronization pays off for regular journeys in delivering key 'moments of truth' (Bitner et al., 2008), and might serve to reduce failure rates, dealing with discrete, atypical journeys, such as resolving baggage handling failures, becomes a discrete service recovery activity. Thus, efforts do not necessarily need to be coordinated. We also see Fraport taking responsibility for errors, but that is because such errors could lead to partner dissatisfaction. This reflects their culture and is important for maintaining their reputation. The Network Rail vignette also shows some breakdown in synchronization during atypical journeys. While actors continue to work together to get the various affected trains to their destination, the outcome is not always beneficial to end users or TOCs, and there is some evidence of Network Rail and TOCs ending up in a 'buck passing' exercise. Interestingly, despite their high synchronization approach, the service experience is probably worse, perhaps because synchronization is enforced by regulation, rather than choice. Thus, we propose:

P4: During atypical journeys, high synchronization strategies mean that supporting actors take greater responsibility for their errors than for low synchronization strategies, and thus, confer benefits on service sellers and improve end-user perceptions of service recovery experiences.

Interaction between visibility and synchronization

Finally, it is important to acknowledge interaction between the two dimensions. For example, low visibility strategies might erode any motivation for synchronization, due to a 
lack of accountability on the part of 'hidden actors'. Invisibility, coupled with low synchronization means that actors are unlikely to coordinate activities, or agree on what is acceptable for a customer's journey, or how to apportion blame (Tax et al., 2013), which could create opportunities for actor misbehavior. Visibility decisions might also be affected by synchronization decisions. For example, high synchronization, where actors cooperate, might mitigate problems associated with low visibility. Hidden actors have no direct customer information, so only tightly coupled strategies are likely to offer benefits for these actors. If firms act independently, they may need to think more creatively about how to build touchpoints with end users, and hence cannot position themselves as simply being a minimal supporting actor (e.g. 'recovery in a crisis'). Thus, the relationships outlined might be more complex than the current propositions suggest.

\section{Conclusion}

The aim of this paper is to provide insights into the potential customer experience management strategies available to supporting actors within service ecosystems. Drawing on extant theory, two key dimensions (visibility of supporting actors and their synchronization with other ecosystem actors) are proposed and a framework developed that delineates six service experience management strategies. These options are explicated using case vignettes to provide insights into the strategies and issues that might arise for these actors, service sellers and end users. High visibility strategies (Northern Powergrid, Fraport Group and UK Rail) appear to offer attractive benefits for all actors, with fewer obvious challenges, but require more resources to be highly visible. Low visibility strategies (UK Power Network, Skeyes, and Menzies) offer some cost benefits, but also challenges 
around credibility and accountability. While theory suggests that these strategies should have benefits relating to having a single, easily recognized actor undertaking most end-user communications, these may only be realized during regular customer journeys.

Furthermore, invisibility might give actors freedom to misbehave. Our insights suggest that it would be prudent for all actors to understand the importance of their strategic choices on other ecosystem actors, to avoid unwelcome surprises. We also contribute to service theory by examining of how different levels of visibility and synchronization are likely to affect service sellers and end-user perceptions during regular and atypical journeys. In particular, the nuanced differences in the implications of these two situations: firms might choose suboptimal positions in one context, to avoid risks attached to the other context, and these choices appear contingent on the type of service.

That said, the paper has some limitations. First, the specific case vignettes offered do not necessarily represent all potential strategic options along the visibility and synchronization dimension. Some actors may have moderate (as opposed to low or high) visibility. Further empirical work will, thus, be necessary to test the propositions, critically examine how the framework applies in practice and refining it to reflect a more nuanced understanding. Second, while we explore visibility and synchronization, other characteristics might be relevant. For example, we have not explored power asymmetries. Third, we have only touched on the timings of becoming visible. Future work might more fully explore issues related to the nuanced differences between more versus less predictable recovery incidents, and more discrete service episodes versus continuous services. Fourth, future work could involve a more detailed examination of institutional arrangements that shape the way ecosystem actors engage in and experience services (Verleye et al., 2017), and the interaction scripts between frontline employees and customers to understand nuanced 
differences that might be required for different strategies. Fifth, we have only considered linear relationships at this point. However, for several of the propositions, non-linear relationships may exist. For example, the relationship between visibility and performance outcomes might be curvilinear, in that visibility is important but only up to an optimal point, beyond which the costs of maintaining visibility outweigh the benefits. Sixth, while service experiences are inherently co-created amongst ecosystem actors (including end users), we have focused on the strategies of supporting actors. Thus, future research could explore the experience management strategies of other types of actors in a service ecosystem.

\section{References}

Adner, R., 2006. Match your innovation strategy to your innovation ecosystem. Harvard Business Review, 84(4), 98-107.

Akaka, M.A., Vargo, S.L., \& Lusch, R.F. (2013). The complexity of context: A service ecosystems approach for international marketing. Journal of Marketing Research, 21(4), $1-20$.

Bitner, M.J. (1992). Servicescapes: The impact of physical surroundings on customers and employees. Journal of Marketing, 56(2), 57-71.

Bitner, M.J., Ostrom, A.L. \& Morgan, F.N. (2008). Service blueprinting: A practical technique for service innovation. California Management Review, 50(3), 66-94.

Burgoon, J.K. (1993). Interpersonal expectations, expectancy violations, and emotional communication. Journal of Language and Social Psychology, 12(1-2), 30-48.

Bustinza, O. F., Lafuente, E., Rabetino, R., Vaillant, Y., \& Vendrell-Herrero, F. (2019). Makeor-buy configurational approaches in product-service ecosystems and performance. Journal of Business Research, 104, 393-401.

Clarysse, B., Wright, M., Bruneel, J. \& Mahajan, A., (2014). Creating value in ecosystems: Crossing the chasm between knowledge and business ecosystems. Research policy, 43(7), 1164-1176.

Connelly, B.L., Certo, S.T. Ireland, R.D. \& Reutzel, C.R. (2011). Signaling theory: A review and assessment. Journal of Management, 37(1), pp.39-67.

Cornelissen, J.P., 2003. Metaphor as a method in the domain of marketing. Psychology \& Marketing, 20(3), 209-225.

De Keyser, A., Lemon, K.N., Klaus, P., \& Keiningham, T.L. (2015). A framework for understanding and managing the customer experience. Marketing Science Institute working paper series, 15-121.

DeWitt, T., \& Brady, M.K. (2003). Rethinking service recovery strategies: the effect of rapport on consumer responses to service failure. Journal of Service Research, 6(2), 193-207. 
Dyer JH \& Singh H. (1998). The relational view: cooperative strategy and sources of interorganizational competitive advantage. Academy of Management Review, 23(4), 660-679.

Fjeldstad, $\varnothing$., Snow, C., Miles, R., \& Lettl, C. (2012). The architecture of collaboration. Strategic Management Journal, 33(6), 734-750.

Gelbrich, K., Gäthke, J., \& Grégoire, Y. (2016). How a firm's best versus normal customers react to compensation after a service failure. Journal of Business Research, 69(10), 4331-4339.

Goffman, E. (1959). The Presentation of Self in. Butler, Bodies that Matter.

Goranova, M., Alessandri, T.M., Brandes, P. \& Dharwadkar, R. (2007). Managerial ownership and corporate diversification: A longitudinal view. Strategic Management Journal, 28 (3), 211-225.

Grove, S.J. and Fisk, R.P., (1983) 'The Dramaturgy of Services Exchange: An Analytical Framework for Services Marketing', in Emerging Perspectives on Services Marketing, 45-49. Berry, Leonard L.; G. Lynn Shostack and Gregory D. Upah, (eds.) Chicago, Illnois: American Marketing Association.

Håkansson, H., Ford, D., Gadde, L.E., Snehota, I. and Waluszewski, A., (2009). Business in Networks. John Wiley \& Sons.

Holt, D.B. and Thompson, C.J., (2004). Man-of-action heroes: The pursuit of heroic masculinity in everyday consumption. Journal of Consumer research, 31(2), 425-440.

Homburg, C., Jozić, D., \& Kuehnl, C. (2017). Customer experience management: toward implementing an evolving marketing concept. Journal of the Academy of Marketing Science, 45(3), 377-401.

Jacobides, M.G., Cennamo, C. and Gawer, A. (2018). Towards a theory of ecosystems. Strategic Management Journal, 39(8), pp.2255-2276.

Joireman, J., Grégoire, Y., Devezer, B., \& Tripp, T. M. (2013). When do customers offer firms a "second chance" following a double deviation? The impact of inferred firm motives on customer revenge and reconciliation. Journal of Retailing, 89(3), 315-337.

Jones, G.H., Jones, B.H., \& Little, P. (2000). Reputation as reservoir: The value of corporate goodwill as a buffer against loss in times of economic crisis. Corporate Reputation Review, 3(1), 21-29.

Keiningham, T. L., Morgeson III, F. V., Aksoy, L., \& Williams, L. (2014). Service failure severity, customer satisfaction, and market share: An examination of the airline industry. Journal of Service Research, 17(4), 415-431.

Kranzbühler, A.M., Kleijnen, M.H., Morgan, R.E., \& Teerling, M. (2018). The multilevel nature of customer experience research: an integrative review and research agenda. International Journal of Management Reviews, 20(2), 433-456.

Kranzbühler, A., Kleijnen, M., \& Verlegh, P. (2019). Outsourcing the pain, keeping the pleasure: effects of outsourced touchpoints in the customer journey. Journal of the Academy of Marketing Science, 47(2), 308-327.

Lemon, K.N., \& Verhoef, P.C. (2016). Understanding customer experience throughout the customer journey. Journal of Marketing, 80(6), 69-96.

Lusch, R.F., \& Nambisan, S. (2015). Service innovation: A service-dominant logic perspective. MIS Quarterly, 39(1), 155-175.

McColl-Kennedy, J. R., Cheung, L., \& Ferrier, E. (2015). Co-creating service experience practices. Journal of Service Management, 26(2), 249-275. 
Meyer, C. \& Schwager, A. (2007). Understanding Customer Experience. Harvard Business Review, February, 117-126.

Möller, K., \& Halinen, A. (2017). Managing business and innovation networks-From strategic nets to business fields and ecosystems. Industrial Marketing Management, 67, 5-22.

Moore, J.F. (1993). Predators and prey: A new ecology of competition. Harvard Business Review, 71(3), 75-83.

Patrício, L., Fisk, R. P., Falcão e Cunha, J., \& Constantine, L. (2011). Multilevel service design: from customer value constellation to service experience blueprinting. Journal of Service Research, 14(2), 180-200.

Patrıcio, L., Gustafsson, A., \& Fisk, R. (2018). Upframing Service Design and Innovation for Research Impact. Journal of Service Research, 21(1), 3-16.

vanReimer, A., \& Folkes, V. (2009). Consumers' inferences about quality across diverse service providers. Psychology \& Marketing, 26(12), 1066-1078.

Swanson, S.R. \& Kelley, S.W. (2001). Service recovery attributions and word-of-mouth intentions. European Journal of Marketing, 35(1/2), 194-211.

Tax, S.S., McCutcheon, D., \& Wilkinson, I. F. (2013). The service delivery network (SDN) a customer-centric perspective of the customer journey. Journal of service research, 16(4), 454-470.

Tiernan, S, Rhoades D.L, \& Waguespack Jr B. (2008). Airline service quality: Exploratory analysis of consumer perceptions and operational performance in the USA and EU. Managing Service Quality: An International Journal. 18(3), 212-24.

Tsoukas, H. (1991). The Missing Link: A Transformational View of Metaphors in Organizational Science. Academy of management review, 16(3), 566-585.

Van den Bulte, C., (1994). Metaphor at work. In Research traditions in marketing (pp. 405434). Springer, Dordrecht.

Van Riel, A., Calabretta, G., Driessen, P., Hillebrand, B., Humphreys, A., Krafft, M., \& Beckers, S. (2013). Consumer perceptions of service constellations: implications for service innovation. Journal of Service Management, 24(3), 314-329.

Van Vaerenbergh, Y., Orsingher, C., Vermeir, I., \& Larivière, B. (2014). A meta-analysis of relationships linking service failure attributions to customer outcomes. Journal of Service Research, 17(4), 381-398.

Van Vaerenbergh, Y., Varga, D., De Keyser, A. \& Orsingher, C., (2019) The Service Recovery Journey: Conceptualization, Integration, and Directions for Future Research. Journal of Service Research, DOI: 10.1177/1094670518819852.

Verleye, K., Jaakkola, E., Hodgkinson, I. R., Jun, G.T., Odekerken-Schröder, G., \& Quist, J. (2017). What causes imbalance in complex service networks? Evidence from a public health service. Journal of Service Management, 28(1), 34-56.

Voorhees, C. M., Fombelle, P. W., Gregoire, Y., Bone, S., Gustafsson, A., Sousa, R., \& Walkowiak, T. (2017). Service encounters, experiences and the customer journey: Defining the field and a call to expand our lens. Journal of Business Research, 79, 269280.

Weill, P., \& Woerner, S. (2017). Surviving in an increasingly digital ecosystem. MIT Sloan Management Review, 59(2), 26-28.

Zolkiewski, J., Story, V., Burton, J., Chan, P., Gomes, A., Hunter-Jones, P., O'Malley, L., Peters, L., Raddats, C., \& Robinson, W., (2017) 'Strategic B2B Customer Experience 
Management: The Importance of Outcomes-Based Measures', Journal of Services Marketing, 31(2), 172-184.

Zomerdijk, L., \& De Vries, J. (2007). Structuring front office and back office work in service delivery systems: an empirical study of three design decisions. International Journal of Operations \& Production Management, 27 (1), 108-131.

\section{Figure}

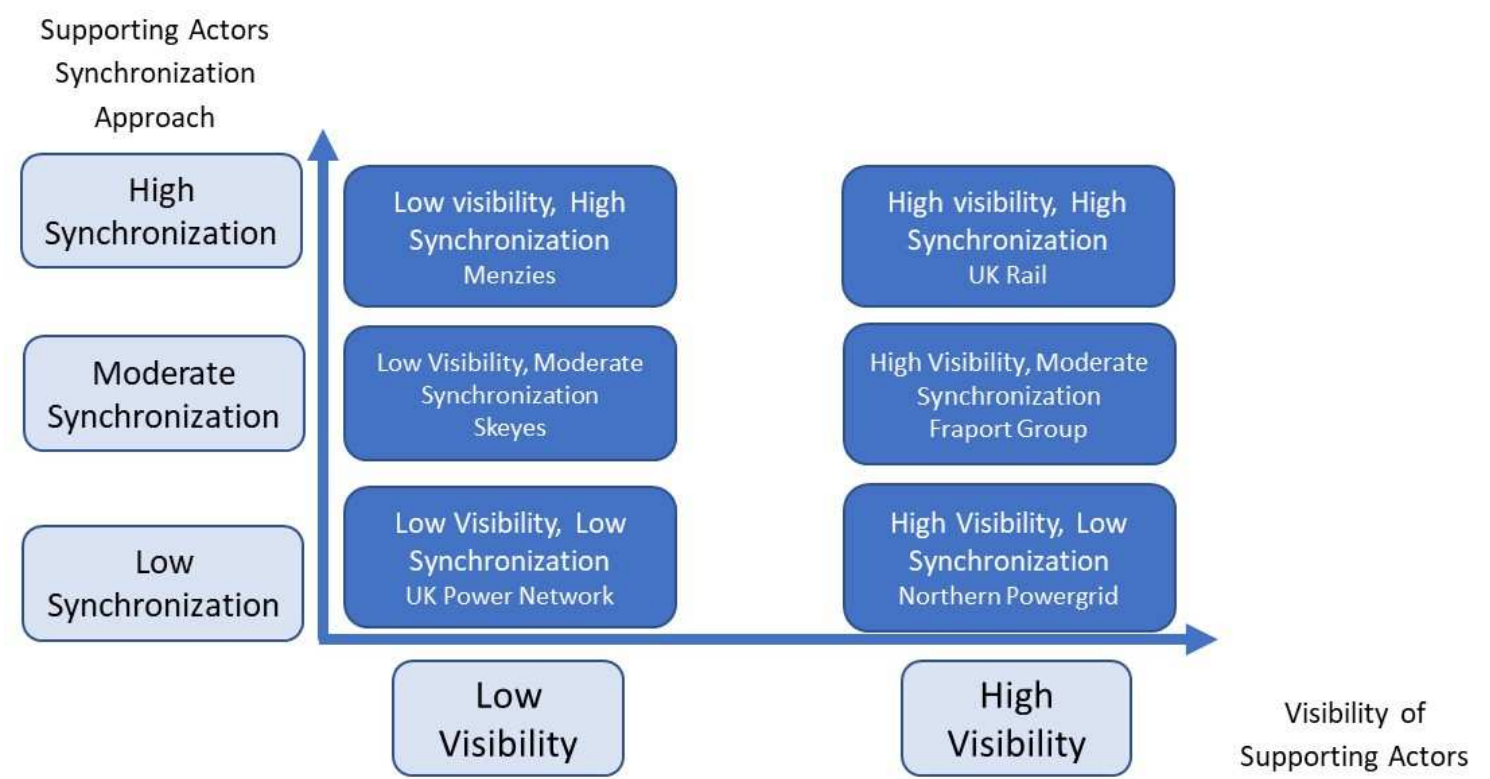

Figure 1: Framework of Supporting Actors Customer Experience Management Strategies 